\title{
HEALTH IMPACT ASSESSMENT: AN INTERNATIONAL PERSPECTIVE
}

\author{
Alex Scott-Samuel \\ International Health Impact Assessment Consortium \\ University of Liverpool \\ United Kingdom
}

The most widely accepted definition of health impact assessment (HIA), from a consensus conference in Gothenburg organised by the World Health Organisation's (WHO) European Centre for Health Policy, defines HIA as 'a combination of procedures, methods and tools by which a policy, programme or project may be judged as to its potential effects on the health of a population, and the distribution of those effects within the population'. ${ }^{1}$ Thus HIA is both a prospective approach (looking at potential effects) and an equity-focused one (looking at distributional impacts - and attempting to prevent inequities that might arise from the policy under consideration). In this article I will refer only to policies, though HIA does of course cover policies, programs and projects.

\section{USES OF HIA}

The explicit purpose of HIA is to make public policies as health-enhancing as possible. It is a prospective decisionsupport tool, not a scientific evaluation method, and its key output is a set of recommendations for modifying the policy under consideration. However, it has other important spin-off effects:

- Health advocacy. HIA is a useful tool for raising awareness of health, especially in the intersectoral context.

- Personal, social and economic development. HIA is very participatory and promotes the personal development of people who undertake it, especially in communities and non-government organisations. Because social and economic development are influenced by social determinants of health, they are enhanced when HIAs are undertaken.

- Advocacy for disadvantaged groups. The focus of HIA on distributional impacts, as well as on whole populations, makes it important in advocating for disadvantaged groups and for partnership building.

\section{ORIGINS AND HISTORY OF HIA}

The origins of HIA were in environmental impact assessment and in health promotion. Environmental impact assessment began in the 1960s and is incorporated into legislation in many countries. HIA principles and methods are based on those developed for environmental impact assessment. The concept of healthy public policy, developed by Nancy Milio ${ }^{2}$ and popularised by the WHO, is about explicitly considering the health impacts of all public policies. In the 1980 s and 1990s it was widely acknowledged that virtually all public policies impact on health. The next step is to estimate or quantify that impact, hence the need for HIA.

While there were examples in the 1980s of environmental health impact assessment and of HIAs of development projects focusing primarily on disease impacts ${ }^{3}$, the first new-style HIA was carried out on the proposed second runway at Manchester airport, England, in 1992-1993. Although this work was not published, it has been influential in the development of methods for HIA.

In 1994, the Ministry of Health in British Columbia, Canada, published a toolkit aimed at enabling civil servants to carry out rapid prospective HIAs of all cabinet policies. ${ }^{4}$ HIA guidelines for regional health boards and community health councils were also produced. In 1995 the United Kingdom (UK) government published Policy Appraisal and Health; this report was produced by health economists and focused primarily on economic aspects of HIA. ${ }^{5}$

The Australian National Health and Medical Research Council took an early interest in environmental HIA, producing its national framework in $1994 .{ }^{6}$ National guidance was also produced in New Zealand and in Canada in 1995. ${ }^{7,8}$ Health Canada also commissioned research on the potential of HIA from the University of British Columbia $^{9}$ and the definition of HIA used in this work later gave rise to the WHO definition.

\section{TABLE 1}

TWO METHODOLOGICAL PERSPECTIVES ON HEALTH IMPACT ASSESSMENT

\begin{tabular}{|c|c|c|}
\hline \multirow[b]{2}{*}{ Dimension } & \multicolumn{2}{|c|}{ Perspective } \\
\hline & Broad & Tight \\
\hline View of health & holistic & definition and observation \\
\hline Disciplinary roots & sociology, epidemiology & epidemiology, toxicology \\
\hline Ethos & democratic & technocratic \\
\hline Quantification & in general terms & towards exact measurement \\
\hline Types of evidence & key informant data & measurements \\
\hline Precision & low & high \\
\hline
\end{tabular}


The first published report of an HIA using the participatory research paradigm relates to the 'People Assessing Their Health' (PATH) project in Nova Scotia, Canada. ${ }^{10,11}$ True participatory research means that the people affected by the issues under study are also involved in every stage of devising, undertaking and following up the research. PATH applied this approach to HIA.

\section{HIA IN EUROPE}

In 1996 I was commissioned by the four Merseyside directors of public health to carry out a program of HIAs. They wanted both to assess the potential health impacts of government urban regeneration programs and to support the development of HIA methodology. In the period 19972000, Liverpool Public Health Observatory published seven reports of completed HIAs, a literature review, and The Merseyside guidelines for health impact assessment. ${ }^{12}$

Following the election of the UK Labour government in 1997 there was strong political support for HIA. In the European context, the momentum for HIA developed following a meeting in Helsinki in 1998, which was part of the European Commission-funded Globalisation and Social Policy Project. Following this meeting, the WHO's European Centre for Health Policy set up a European HIA e-mail discussion group and subsequently established fellowships and seminars, commissioned monographs and organised the Gothenburg consensus conference. All of this activity can be attributed to the leadership shown by the Centre's former Director, Dr Anna Ritsatakis.

It is important not to see HIA solely as a tool of government. The ways in which it can be used depend on who is using it. For example, if a private company or the World Bank commissions an HIA, the implications will be different to those when the WHO, the Australian government, a health promotion unit or a community group in a small town in NSW is the commissioner.

\section{METHODOLOGICAL PERSPECTIVES}

John Kemm wrote a guide to HIA for the National Assembly for Wales in which he described two alternative methodological perspectives (Table 1). ${ }^{13}$ Most HIAs fall somewhere between these two extremes. I would propose that broader HIA perspectives are appropriate, since they are more participatory and more likely to avoid the common tendency toward unjustifiable quantification of predicted impacts (evidence which is sufficient to justify the quantification of impacts, preferably with confidence limits, remains the exception rather than the rule in HIA).

\section{MODELS OF HEALTH}

HIA requires a comprehensive model of health causality on which to base the prediction of impacts. The Merseyside Guidelines draw on a model originally produced by Ron Labonté ${ }^{14}$, from which are derived the range of health determinants used in impact prediction (Table 2). ${ }^{15}$ The aim is to consider the full range of biological, material and social determinants of health when predicting impacts.

\section{THE MERSEYSIDE APPROACH- HIA PROCEDURES AND METHODS}

The Merseyside Guidelines use a series of procedures and methods. Screening involves a systematic procedure for selecting those policies requiring HIA. However, in many cases an HIA on a specified policy is commissioned and screening is not required. In other cases a rapid screening is sometimes used as a substitute for undertaking an HIA. The screening procedure in the Merseyside Guidelines uses economic, epidemiological and strategic criteria, in addition to criteria relating to probable impacts of the policy.

A steering group of stakeholders is useful in all HIAs other than the briefest desktop exercises. The steering group defines the terms of reference of the HIA, which set its boundaries in time and in space. Consideration of potential

\section{TABLE 2}

\section{HEALTH IMPACT CATEGORIES AND DETERMINANTS}

\begin{tabular}{|c|c|}
\hline Health impact categories & Examples of specific health determinants \\
\hline Biological factors & age, sex, genetic factors \\
\hline Personal or family attributes and conditions & $\begin{array}{l}\text { family structure and functioning, =g behaviour, diet, smoking, alcohol, substance misuse, } \\
\text { exercise, recreation, means of transport (cycle/car ownership) }\end{array}$ \\
\hline Social environment & $\begin{array}{l}\text { culture, peer pressures, discrimination, social support (neighbourliness, social networks/ } \\
\text { isolation), community/cultural/spiritual participation }\end{array}$ \\
\hline Physical environment & $\begin{array}{l}\text { air, water, housing conditions, working conditions, noise, smell, view, public safety, civic } \\
\text { design, shops (location/range/quality), communications (road/rail), land use, waste disposal, } \\
\text { energy, local environmental features }\end{array}$ \\
\hline Public services & $\begin{array}{l}\text { access to (location / disabled access / costs) and quality of primary/community/ secondary } \\
\text { health care, child care, social services, housing / leisure / employment / social security } \\
\text { services, public transport, policing, other health-relevant public services, non-statutory } \\
\text { agencies and services }\end{array}$ \\
\hline Public policy & $\begin{array}{l}\text { economic/social/environmental/health trends, local and national priorities, policies, } \\
\text { programmes, projects }\end{array}$ \\
\hline
\end{tabular}


impacts of radiation, smoking or asbestos makes it apparent that the setting of spatial or temporal boundaries for an HIA may not be straightforward.

The key steps in an HIA involve conducting and appraising the assessment, negotiating favoured options and making recommendations for policy implementation. Following this, the policy outcomes are monitored and the HIA process is evaluated and documented. HIA methods begin with analysis of the policy content and context, and profiling of potentially affected populations — especially disadvantaged or vulnerable population groups. Following this comes the fieldwork-eliciting impact predictions from stakeholders and key informants, including local communities, policy proponents, professionals and experts.

HIA fieldwork employs a range of qualitative techniques, most commonly interviews and focus groups, but also scenarios and consensus techniques such as Delphi exercises and consensus conferences. Quantitative methods such as economic forecasting and mathematical modelling may be employed. 'Rapid HIA' frequently omits this primary data collection or reduces it to a single stakeholder 'workshop'.

These processes, together with the results of literature searches of earlier policy outcomes, establish potential impacts. These are prioritised on the basis of their predicted severity, magnitude and probability of occurrence. Recommendations are then formulated-sometimes following an option appraisal-to modify the policy to make it optimally health-enhancing, and to mitigate identified problems where necessary.

\section{METHODOLOGICAL CONTROVERSIES}

\section{Science and politics}

HIA is not a scientific evaluation method, it is a decisionmaking procedure that draws on a scientific knowledge base-essentially it is a political tool. The science in HIA is in the evidence base and in the systematic approach. Thus HIA is historically specific, it is not repeatable or generalisable. Some disagree with this broad perspective and see HIA in a more reductionist, quantitative way.

\section{Values}

Some HIA practitioners perceive HIA as value-free. My position is openly value-laden: equity and democracy are the most obvious values underlying HIA. Transparency about prior values is essential.

\section{Expertism and participation}

The Merseyside Guidelines describe a liberal expertist approach allowing different degrees of participation. In practice we see the involvement of affected people as crucial to the effectiveness of HIA. Others find participation difficult and dispensable ${ }^{16}$, a view I would strongly contest.

\section{Duration and depth}

Duration and depth need to be separated because people talk about 'rapid HIA' when they mean more superficial (as opposed to more comprehensive) HIA. There is a trade-off between duration and depth, for example if you have a month to do an HIA and you have 10 staff, they may achieve more than would be achieved by one person working for six months.

\section{Equity and equality}

Equality principles can be applied to all HIA methods; equity can be incorporated through public involvement, valuing the views of so called lay people and in the choice of paradigm.

\section{CONCLUSION}

Although still in its infancy, HIA would appear to have a rosy future, particularly if it is widely adopted by international organisations such as the United Nations, and in the United States. While the United Nations World Health Organization has formally adopted HIA both in its own activities and in its Commission on Social Determinants of Health, the United Nations has not as yet acknowledged the potential of HIA in relation to its central concerns such as global public policy ${ }^{17}$ and human rights..$^{18}$ In the United States, arguably the most powerful global actor, the process of adopting HIA is in its early stages. ${ }^{19}$ In both of these contexts, the building of capacity and capability will be a limiting factor.

\section{REFERENCES}

1. WHO European Centre for Health Policy. Health Impact assessment. Main concepts and suggested approach. Gothenburg consensus paper. Copenhagen: WHO Regional Office for Europe, 1999.

2. Milio N. Promoting health through public policy. Philadelphia: FA Davis, 1981.

3. Birley M. The health impact assessment of development projects. London: HMSO, 1995.

4. Population Health Resource Branch. Health impact assessment toolkit: a resource for government analysts. Victoria, British Columbia: Ministry of Health, 1995.

5. Department of Health. Policy appraisal and health. London: Department of Health, 1995.

6. Ewan C, Young A, Bryant E, Calvert D. National framework for environmental and health impact assessment. Canberra: National Health and Medical Research Council, Australian Government Publishing Service, 1994.

7. Public Health Commission. A guide for health impact assessment. Wellington: Public Health Commission, 1995.

8. Davies K. National health guide for environmental assessment. Ottawa: Ministry of Health, 1995.

9. Frankish C, Green L, Ratner P, Chomik T, Larsen C. Health impact assessment as a tool for population health promotion and public policy. Vancouver: Institute of Health Promotion Research, University of British Columbia, 1996. 
10. Gillis D. The people assessing their health (PATH) project: tools for community health impact assessment. Can J Public Health 1999; 90(Suppl): S53-S56.

11. Mittelmark M, Gillis D, Hsu-Hage B. Community development: the role of HIA. In: Kemm J, Parry J, Palmer S, eds. Health impact assessment. Oxford: Oxford University Press, 2004: 143-52.

12. Liverpool Public Health Observatory HIA reports. At: www. liv.ac.uk/PublicHealth/obs, accessed 16 August 2005.

13. National Assembly for Wales. Developing health impact assessment for Wales. Cardiff: Health Promotion Division, National Assembly for Wales, 1999.

14. Labonté R. Health promotion and empowerment: practice frameworks. Toronto: Toronto Centre for Health Promotion, University of Toronto and ParticipAction, 1993.
15. Scott-Samuel A, Birley M, Ardern K. The Merseyside guidelines for health impact assessment. $2^{\text {nd }}$ edition. Liverpool: IMPACT, University of Liverpool, 2001. Available from www.ihia.org.uk/document/merseyguide3.pdf.

16. Parry J, Wright J. Community participation in health impact assessments: Intuitively appealing but practically difficult. Bull World Health Organ 2003; 81: 388.

17. O'Keefe E, Scott-Samuel A. Health impact assessment and globalization. In: Kawachi I, Wamala S, eds. Globalization and health. New York: Oxford University Press (in press).

18. O'Keefe E, Scott-Samuel A. Human rights and wrongs: Could health impact assessment help? J Law Med Ethics 2002; 30: 734-8.

19. Dannenberg A et al. Growing the field of health impact assessment in the United States: An agenda for research and practice. Am J Public Health (in press).

\section{HEALTH IMPACT ASSESSMENT IN AUSTRALIA}

\section{Mary Mahoney \\ HIA Research Unit \\ Deakin University}

A recently published paper which describes the status of health impact assessment (HIA) in Australia in 2003 provides a vantage point from which to see how rapidly HIA is developing across the country. ${ }^{1}$ When the report Health impact assessment: a tool for policy development in Australia was released in 2002 there was little use of HIA beyond environmental management applications. ${ }^{2}$ By late 2005, most states and territories are undertaking a variety of HIA activities either routinely or experimentally. Traditional divisions between environmental project-level applications that focus on health protection and public health policy-level applications that focus on health promotion, are largely disappearing. These are being replaced by a growing understanding of the need for complementarity in approach and cross-sectoral working. This is not to say that there are high levels of activity, but both awareness and action are increasing.

In terms of the development of HIA in Australia, the period between 1999 and 2003 was characterised by a desire to strengthen the health component in environmental assessment processes and procedures, broaden the interpretation of health through the introduction of the enHEALTH Health Impact Assessment Guidelines $(2001)^{3}$ and commence discussions about the strategic positioning of HIA as a tool for use by governments. In 2004 two national events helped to strengthen intersectoral understanding of HIA: a three-day national HIA workshop in Brisbane co-hosted by the Queensland Public Health Forum, the National Public Health Partnership (NPHP), Queensland Health and enHEALTH and a two-day equity-focused HIA workshop in Sydney hosted by the Australasian Collaboration for Health Equity Impact Assessment
(ACHEIA) and funded by the federal government and NSW Health. Both events allowed for jurisdictional and crossdisciplinary conversations about work being undertaken and the exploration of enablers and barriers. They also provided the chance for a deeper understanding of HIA and its future role to be developed.

The list of developments in the field of HIA that are described in this article has been collated from three sources: submissions prepared by each jurisdiction for the Brisbane conference; state submissions on HIA for inclusion in a national HIA poster presented at the $6^{\text {th }} \mathrm{UK}$ and Ireland HIA Conference in late 2004 ${ }^{4}$; and presentations of completed HIAs and case studies delivered at both these conferences.

\section{EMERGING TRENDS IN HIA ACROSS AUSTRALIA}

- Intersectoral action and partnership working - this is occurring at two levels: organisational and professional. At the organisational level, consortia of organisations such as local and state governments, developers, researchers and community representatives are working together to explore the health impacts of large urban developments, including developmental work in NSW and Queensland. At the professional level, individuals and teams of people (for example, land use planners, statutory planners, strategic planners, public health planners and community health planners) are beginning to work together as the links between their respective roles is increasingly being articulated, both within and between organisations.

- A focus on community regeneration-exploration of the role of HIA in the planning stages of state government regeneration schemes in disadvantaged communities, particularly developmental work in NSW 